\title{
Liberating Mental Health in IR 5.0 through Holistic Education
}

\section{Sheela Jayabalan, Daleleer Kaur Randawar \& Nur Ezan Rahmat}

To Link this Article: http://dx.doi.org/10.6007/IJARBSS/v11-i11/11098 DOI:10.6007/IJARBSS/v11-i11/11098

Received: 03 September 2021, Revised: 04 October 2021, Accepted: 26 October 2021

Published Online: 24 November 2021

In-Text Citation: (Jayabalan et al., 2021)

To Cite this Article: Jayabalan, S., Randawar, D. K., \& Rahmat, N. E. (2021). Liberating Mental Health in IR 5.0 through Holistic Education. International Journal of Academic Research in Business and Social Sciences, 11(11), 2243-2264.

\section{Copyright: @ 2021 The Author(s)}

Published by Human Resource Management Academic Research Society (www.hrmars.com)

This article is published under the Creative Commons Attribution (CC BY 4.0) license. Anyone may reproduce, distribute, translate and create derivative works of this article (for both commercial and non0-commercial purposes), subject to full attribution to the original publication and authors. The full terms of this license may be seen at: http://creativecommons.org/licences/by/4.0/legalcode

Vol. 11, No. 11, 2021, Pg. $2243-2264$

Full Terms \& Conditions of access and use can be found at http://hrmars.com/index.php/pages/detail/publication-ethics 


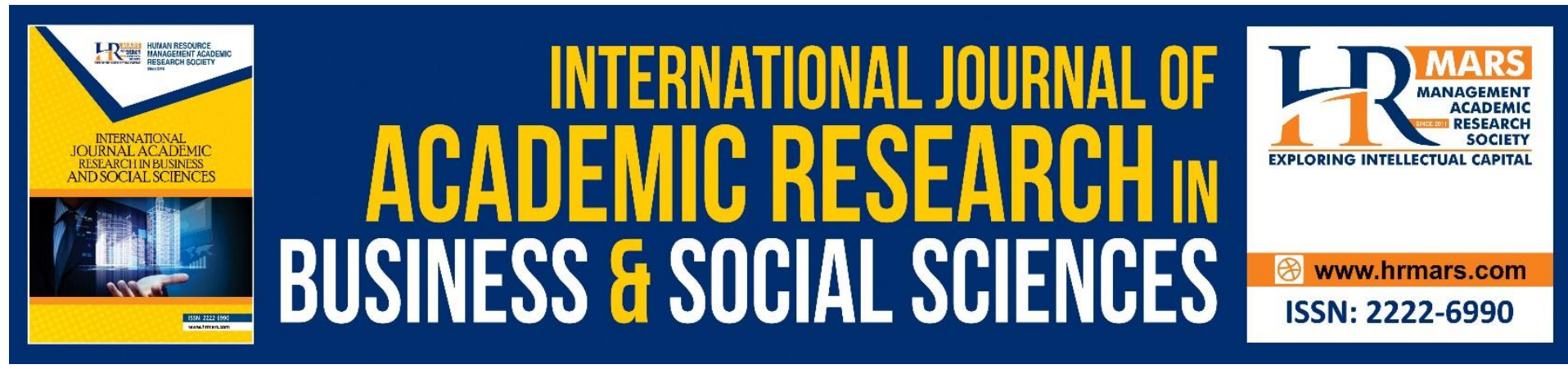

\title{
Liberating Mental Health in IR 5.0 through Holistic Education
}

\section{Sheela Jayabalan, Daleleer Kaur Randawar \& Nur Ezan Rahmat}

Faculty of Law, Universiti Teknologi Mara (UiTM), 40450 Shah Alam, Selangor Darul Ehsan, Malaysia.

\begin{abstract}
Introduction: Industrial Revolution 5.0 sees man and machine working in harmony. The life of a human is often dictated by emotions. Relationship with machines, however, disconnects one from emotions, thus adversely affecting the mental health of humans causing mental conditions such as depression, anxiety disorders, schizophrenia, schizoaffective disorders, bipolar disorder and autism spectrum disorder. To address mental health, education should pave the way for children to attain and sustain mental wellness specifically through holistic education. Holistic education is based on the premise that each person finds identity, meaning, and purpose in life through connections with the community, the natural world, and spiritual values such as compassion and peace, which is also known as cosmic intelligence. Holistic education should be included in the education system in Malaysia to prepare a child to meet the challenges that Industrial Revolution 5.0 may pose. Adopting a conceptual research, qualitative methodology, this article pre-supposes that holistic education be integrated in the school curriculum in Malaysia as a measure to help children attain and maintain mental wellness. The holistic education curriculum should be elucidated as a wellness model with the objective of constructing strong mental health to prepare the future generation to meet the challenges and the needs of the industry revolution. Mental health should not be treated as an illness but as a state of well-being where individuals get to realize their abilities to cope with the normal stressors of life and work productively for the betterment of oneself and the general community.

Keywords: Mental Health, Emotional \& Intelligence Quotients, Liberating, Holistic Education, Industrial Revolution
\end{abstract}

\section{Introduction}

A national survey by the Ministry of Health has revealed that Malaysian teenagers aged between 13 and 17 years old suffer from mental health problems such as depression, anxiety disorders, schizophrenia and schizoaffective disorders, bipolar disorder and autism spectrum disorder ("National Health and Morbidity Survey", 2011). Some children, who cannot manage the emotional distress, choose to commit suicide or hurt themselves, or even display psychopathic behaviours by committing heinous crimes. 
There are others who resort to substance abuse such as alcoholism or drug abuse which is very rampant especially among teenagers. Succumbing to peer pressure, family problems and surrounding circumstances, teenagers' resort to substance abuse to blanket their problems. Consequently, affecting their mental wellbeing. Since suicide is mainly seen as a medical or psychiatric concern i.e., mental illness or mental disorder is a major cause for concern especially when suicide cases are prevalent among children in Malaysia. Between 2014 and 2018 it was revealed that 1,696 people died committing suicide, while 625 attempted to end their lives in Malaysia as reported in the New Straits Times, 2018. The Ministry of Health highlighted the occurrence of suicidal thoughts in $10 \%$ of the student population, which is an increase by 3.1\% from 7.9\% in 2012 (New Straits Times, 2018) and the age of students who attempt to commit suicide is getting younger. Most suicidal attempts by students are caused by mental health issues such as depression. Whereas human capital is only productive if society is mentally fit. Emotional and mental health is important because it is a vital part of a person's life since it impacts thoughts, behaviours, and feelings. If an individual is emotionally healthy, he or she should be able to increase productivity and efficacy in daily activities which include workplace tasks and activities that conforms to the needs of the industry. A stable and healthy state of mind also allows a person to adapt to changes in life and cope with any adversity initiated by the industry. Industrial revolution 5.0 involves mankind getting connected with machines and optimizing them to complete a task. Hence, society will evolve from one that is information-based in Industry 4.0 to one that is super smart in Industry 5.0 that deals with robots, artificial intelligence and big data. The main concern of the authors is, the interrelationship between man and machine will disconnect mankind from one another. As relationships with machine do not embrace emotions such as compassion, love and care, diplomacy, empathy etc., people may become totally disoriented and disconnected with humanity as reflected in the science fiction movie 'Ready Player One'. In this movie, society is given the freedom to choose with whom and where they want to be in a fictional world named Oasis. People transform into their preferred avatars and live in an imaginary world where they trade, travel, marry, divorce, fight, kill and die, all of which demonstrate a complete disconnection with the real world. The Oasis becomes the ideal 'space' to live as earth is in a state of disorder. As humans are so subsumed to the imaginary world, innovative online industries (IOI) capitalize and controls the Oasis through their invention of games that monopolizes the society. People live in sate of delusion in this movie. Although this movie is merely science fiction, it depicts the future of industrial revolution where society live in a disillusioned state of life and disconnected from humanity and spirituality. This factor if left unattended, it may affect the mental health of the future generation. One of the means to sustain healthy mental state of mind, emotional intelligence through holistic education should be absorbed by the education system. Literature reviewed states that holistic education frequently claims that it desires to educate the child as a whole and see the child as part of a society, humanity, the environment and the cosmos. In other words, holistic education should better prepare a child mentally to face any challenges that Industry 5.0 may pose, and scholars have concurred that holistic education is the education for the $21^{\text {st }}$ century.

Even though the occurrence of mental health issues among students are caused by many factors such as peer pressure, harsh parenting styles, family conflicts, and societal expectations, one causal factor that has been overlooked is the education system itself to function as a tool to address mental health and prepare the younger generation for the 
demands of the industrial revolution. Historical analysis indicates that the education system is interconnected with the needs brought about by the industrial revolution and to meet them, human capital is critical. This is attained through an effective education system which leverages the workforce to respond to the many facets of industrial revolution. For example, factory-based schools suited for the Industrial Revolution 1 and 2, paved the way for technology-based schools which emphasized cognitive capital to complement the evolution of science and technology. Though the inter-relations of industrial revolution and human capital are inevitable, the mental health of human capital faces a setback. This is a major cause of concern that should be addressed in Malaysia and globally.

An ideal tool to promote a healthy state of mind to meet the demands of and prepare the younger generation for Industrial Revolution 5.0 should be through holistic education with the objective of achieving emotional intelligence instead of emphasizing on intelligence quotient which is the current practice in Malaysia. The genome of human capital should be shaped psychologically and be equipped with emotional intelligence to face the challenges of Industry 5.0 through holistic education. This factor is a lacuna in the Malaysian education system that needs to be addressed. As Andreas Schleicher, Director of the OECD Directorate for Education and Skills, commented in 2019, he said, "education is not only about enriching students with knowledge. Education should be a lifelong learning process that equips the child to be independent and apprehend the challenges of life." Therefore, the authors promulgate that the education system should undergo a transformative change in Malaysia. Schools in Malaysia should aspire to operate a holistic-based curriculum that recognizes the need for interdependence and broadens the goals of education that deals with the mental health of the younger generation to adapt to the forthcoming industry revolution. Such a curriculum should recognize the differences among students and acknowledge that each student has different prior knowledge and skills, as well as diverse attitudes and values. This muchneeded shift is required in the Malaysian education system. Finland, for example, introduced 'Phenomenal Education' that stresses on holistic real-world phenomena to promote nonlinear learning paths rather than a linear progression along a single, standardized path. The 'Phenomenal Education' system should be bench marked to make changes in the Malaysian education system if holistic education is to be implemented. Therefore, the objectives of this article are:

- To highlight the importance of mental health in IR 5.0;

- To discourse holistic education as a non-linear path to address mental health concerns in Malaysia;

- To propose holistic education in the Malaysian education system by benchmarking the 'Phenomenal Education' system in Finland.

\section{Industrial Revolution, Education and Mental Health: The Correlation}

The industrial revolution saw the need for public education. Skilled human capital necessitated education. Educators, however, believed the education system during the Industrial Revolution was based on the factory model of education that limited education to solely train future factory workers. The belief was that children were solely prepped to learn essential skills required to become a competent factory worker. Students therefore, were not grouped based on their abilities, but rather their chronological age and the demands of 
the industry. Alvin Toffler who criticized the "Industrial Era School" in his 1974 book stated that, "Mass education was the ingenious machine constructed by industrialism to produce the kind of adults it needed." As industrial needs became competitive and advanced, education that turned agrarian human capital to skilled factory workers was not sufficient especially with the progress of science and technology. Society was compelled to face the evolution of industrial revolution and be proficient in science and technology. The school system, therefore, was revamped to accommodate the needs of the revolution. The focal point or emphasis of education, however, was to prepare an individual for work to suit the many phases and evolution of industrial revolution. The education system however, overlooked the importance of mental health. Reports of adults and children committing suicide, an increase in the number of people suffering from mental disorders such as anxiety, depression, schizophrenia and schizoaffective disorders, bipolar disorders, reports of heinous crimes committed by adults and children, abnormal reports of sexual behaviours and bullying are several indicators that mental health needs attention. Mental health and well-being are of primary concern that should be addressed and should be approached as a salutogenic or wellness model in schools. No doubt a child's well-being and mental health starts with family upbringing. But as a preventative measure, the importance of mental health should be reinforced from the time children attend school. According to the Freudian theory, children are relatively helpless and dependent on their parents for love, care, security, support and are emotionally unstable. This theory postulates that children lack the ability to cope with emotional traumas, deprivations, and frustrations because of their young age and vulnerable state of mind. Consequently, suppression of intrapsychic conflicts that the young person holds increases the likelihood of insecurity, unease, or guilt that will subtly influence the developing personality in adult life, thus affecting the person's interests, attitudes, and ability to cope with future stressors. Therefore, apart from parental guidance, the education system should address mental wellness from childhood as suggested by WHO. Holistic education should be the way forward because its foundation shapes humanity, culture, spirituality, and relationship with the environment. Social relationships, cultural and environmental exposure should start from school as core values. To urge individuals to stay connected with humanity and spirituality regardless of what industrial revolution brings, holistic education should be built into the education system to develop emotional intelligence i.e., mental wellness. Though Industrial Revolution 4.0 and 5.0 transcend automation and machinery compared to Industry 3.0 through smart systems using data and machine learning, the internet of Things (IoT) and Artificial Intelligence (Al) that necessitate intellectual human capital, it also causes mental fatigue. To achieve an equilibrium between invoking cognitive skills to conform to the needs of Industry 4.0 and the future of Industry 5.0 and mental health, a holistic education system should be incorporated into the education curriculum. Preferably, in Malaysia the education system should be more flexible and personalized to ensure that each student's unique talents are developed to his or her full potential to support intellectual and psychological development. Only if mental health is attained in the era of industrial revolution, can the current and future generation conform to and evolve with its demands. Holistic education is significant because it deals with the development of a person's intellectual, emotional, social, physical, artistic, creative, and spiritual potentials which comprise both emotional and intellectual quotients which are indispensable for the future of Industry 5.0. 


\section{Liberating Mental Health in Industry 5.0 Through Holistic Education and Benchmarking 'The Phenomenal Education' System in Finland: A Discourse}

Ron Miller, 1997, one of the leaders of the holistic education movement stated that, holistic teaching does not refer to a specific methodology. Instead, it should be seen as a collection of fundamental assumptions and values that can be seen in a variety of ways, which is not implemented in the current mainstream education in Malaysia. The education system in Malaysia conforms to a "mechanistic" or "Cartesian-Newtonian" as with most parts of the world. Generally, though the "Cartesian-Newtonian" curriculum is not the sole cause for mental disorders among children or adults who have undergone education under this traditional system, nonetheless the demands of this system and the industry have pressured school children to suffer from mental disorders such as anxiety, depression, schizophrenia and schizoaffective disorders, bipolar disorders which have consequently led to other negative repulses such as suicidal attempts, substance abuse, alcoholism, sadistic behaviour and additional disorderly behaviours because of their incapability to acclimatise. To address this concern, holistic education should be weaved into the current education system to achieve both emotional and intellectual intelligence in Malaysia. Only then children will be accustomed to any changes, challenges and expectations brought about by Industry 5.0. Moreover, in the view of a philanthropist, Swami Vivekananda, the philosophy of education should not be a mere accumulation of information but instead a comprehensive training for life. To quote him: "Education is not the amount of information that is put into your brain and runs riot there undigested, all your life." Education for Swami Vivekananda, is a process by which character is formed, strength of mind is increased, and intellect is sharpened to assist a person to stand on one's own feet.

The education system from primary education to tertiary education in Malaysia does not place sufficient importance on emotional intelligence. The emphasis of education is on intellectual intelligence. School children in Malaysia are not taught values to help build emotional strength but instead taught common values representing good character such as: respecting religion, culture and custom, adhering to the law and the King, respecting the elderly etc. The education curriculum is exam-oriented and students are pressured to perform with excellence. Preventative measures to address mental health is not of primary importance. As a result, children who are victims of abuse or bully, suffer in silence. Mental health is an aspect that is often overlooked, especially in schools in Malaysia. An evident exampleis the report of seven Orang Asli (indigenous natives of Malaysia) children who ran away from a boarding school in Gua Musang, Kelantan in 2015. Out of the seven children, five died tragically. These children were said to run away because they could not comprehend the school education curriculum. They were upset that they had been found even though they were lost and traumatised. This tragic incident highlights that the education system failed to help the native children acclimatise to mainstream education because it disconnected the children from the native's way of life. The natives of any region for the matter are closely related to the environment. The natives however, are forced to adapt to the mainstream lifestyle because their livelihood has been threatened by progress and development. For example, it was reported in Kampung Ulu Penderas, the family of Bah Sali (orang Asli family) are facing an uncertain future because of land encroachment. This hardworking family earns MYR350-450 a month through forest resources, tapping rubber and harvesting oil palm branches, but their livelihood is now affected because the Perak State Agriculture Development Body (Perbadanan Pembangunan Pertanian Negeri Perak) 
has cleared their fruit orchard for plantation as reported in the The Star, 12 March 2019. Likewise, little thought is given to the suitability of mainstream education that is being imposed on the native children and the natives as a whole. This could be one of the reasons why orang Asli children are not keeping up or adapting with the education system in Malaysia. The mainstream education system in Malaysia conforms to formal education which is overt-based. Overt-based curriculum is confined to instructional written directions such as a curriculum document, texts, films, and supportive teaching materials that are overtly chosen to support the intentional instructional agenda of a school. Overt-based curriculum is evident from the goals of National Education which are to produce a united 'Bangsa Malaysia'; to produce Malaysian citizens who are knowledgeable, God-fearing, wellbehaved, competent and harmonious to provide a capable work-force to meet the needs of a growing nation and to offer equal educational opportunities for all Malaysian citizens. The education system, however, in reality accentuates a knowledge-based, exam-oriented education system with no thought or consideration for one that is holistic. The current orientation of education is to train children for global market consumption evident from the multidisciplinary and cross-disciplinary programs offered especially at tertiary level. As aptly pointed out by Kincheloe, "that corporations are now the most prominent source of the cultural curriculum in America. No longer are schools, churches, and family's dominant in the education of young people. Corporations are." In Malaysia, though Industry 4.0 mentions the surge for holistic qualities, the education system remains unchanged. What more during the Covid-19 pandemic, when the movement control order (MCO) was declared, the education system came to a standstill. Both children and teachers were not equipped and ill prepared to learn and teach from home the mainstream school curriculum. To make matters worse, there were reports that the mental health of children was affected or is at potential risks because during the lockdown routine norms such as playing with friends, sport activities, daily interactions and teaching face to face was forbidden when the country went into lockdown. Children were forced to observe standard operating procedures when school re-opened for a short span of time during conditional movement order in Malaysia. Some children would have witnessed their loved ones succumbing to the Covid-19 pandemic. These factors undeniably would cause mental stress especially among children upsetting their mental health and well-being. Therefore, mental health is not only important to meet the demands of the industry but also to face supervening events such as the pandemic. One of the means of liberating mental health through holistic education however is still in a state of illusory because the emphasis of education in Malaysia is knowledge based. Meanwhile, advocates of holistic education such as Clark (1991) is of the view that, "by introducing students to a holistic view of the planet, life on Earth, and the emerging world community, as a context of meaning," will enable students to perceive and understand the various contexts which shape and give meaning to life. Rudolf Steiner and Maria Montessori the two most prominent holistic educators transcended the education system to a new vanguard. The Waldorf educational system which embeds the rudiments of holistic philosophy was created by Rudolf Steiner, an Austrian philosopher and scientist. Steiner advocates anthroposophy (a source of spiritual knowledge and a practice as a path of inner development). In his words, he stated that, "the idea that children who consciously cultivate independent thinking will be more ready to handle the important natural and spiritual questions with which philosophers and scientists are concerned." Likewise, Maria Montessori ("The Montessori method", 1965) believed that every educator should "follow the child", recognizing the evolutionary needs and characteristics of each age, and building 
a favourable environment, both physical and spiritual, to respond to these needs. Children's development emerges as a need to adapt to the environment. Holistic education emphasises on educating an individual to know oneself and appreciate the blessings of life and the importance of being interconnected to oneself and others. It discourages selfishness, cruelty, and seeks to educate the whole person with love, respect, and care. As Krishnamurti ("Education and the Significance of Life, Pondicherry, India", 1974) said, "If the unity of life and the oneness of its purpose could be clearly taught to the young in schools, how much brighter would be our hopes for the future!" According to Scott Forbes, 2003, holistic curriculum is stated to be crucial for four reasons as follows; "Firstly, children need to learn about themselves; Secondly, children need to learn about relationships. In learning about their relationships with others, there is a focus on 'social literacy' (learning to see social influence) and 'emotional literacy' (learning to see one's own self in relation to others); Thirdly, children need to learn about resilience. This entails overcoming difficulties and facing challenges and fourthly; children need to learn about aesthetics, to see the beauty of what is around them and experience a sense of awe in its presence." The four reasons as stated by Scott Forbes, accentuates the importance of incorporating holistic education in the school curriculum system in Malaysia. Finland has taken a bold step by implementing a phenomenal-based teaching which incorporates holistic teaching that strives for equity and encourages non-standardized tests. Viewing phenomena from the viewpoints of multiple different subject-based disciplines helps students to see the world in its complexity and seek out inclusive solutions to complex problems. Hence, students are equipped to be emotionally and intellectually intelligent. As stated by Soby (2015), in Finland, the seven learning goals of transversal competence are; "C1. Thinking and learning to learn; C2. Cultural literacy, interaction, and expression; C3. Taking care of oneself, everyday life skills, safety; C4. Multi-literacy; C5. Digital competence; C6. Working life skills and entrepreneurship; C7. Participation, influence, and responsibility for a sustainable future. The emphasis of Finnish education is on strengthening emotional intelligence because emotional intelligence develops the mental wellness of a child to face the demands and challenges of not only the industry but most importantly life in their adulthood. Literature review supports the view that emotional intelligence should be given eminence in Malaysia. In the authors' view the education curriculum should encourage students to think about their decisions and how they affect the global and local communities, as well as how to learn from others in school. Teachers should assign students with formative assessments that requires them to use logical thinking techniques to solve real-world issues instead of the current mechanistic learning culture which is deeply rooted in the Malaysian education system. An enquiry-based and constructivist methods of teaching should be cultivated. Learning only the theory often results in a superficial understanding. Life practices should be integrated in a pedagogical framework where individuals can truly participate in the learning process. The authors suggest that Maria Montessori's self-motivated growth philosophy and Rudolf Steiner and Emil Molt's Waldorf experiential learning technique should be imbibed in the school curriculum of Malaysia that should improve academic achievements as well as enhance mental and emotional well-being of the children. Furthermore, holistic education should also be instilled to cultivate problem solving skills in children and reduce inequities because of the whole-child approach in holistic education. 


\section{Conclusion}

Mental wellness should be achieved and prioritized to prepare the current and future generation not only to embrace the forthcoming industrial revolution but also to build a learning society that is devoid of ego, ignorance and all other false identifications, which stand in the way to self-realization. Human beings are not machines but are infused with feelings and emotions. Hence, it is imperative for an individual to stay connected with oneself to face the challenges of the future especially if the future industry is going to disconnect mankind from one another. Attaining and maintaining mental wellness, therefore, should be a continuous endeavour for the forthcoming era. One of the methods to achieve mental wellness is through a holistic education which should be integrated in the school curriculum because school is an institution where children spend most of their time to obtain knowledge. The knowledge obtained in school however is not only academic knowledge but it is also a place where children pick up negative habits and knowledge such as lying, bullying, being disrespectful, substance abuse, sex addiction, crimes and other social ills. If the bad habits are not attended to and addressed, child delinquency, a societal denominator for a maleficent child becomes a cause for concern. Education should not prioritise imbibing the children of the future to merely strive for academic excellence that does not invigorates the inner strengths and emotions of a child. Education should invoke the creativity in a child that probes the higher order thinking capacity and cultivates emotional intelligence. As stated by Narve, 2001, to prepare children to face the real world, they need to be groomed to recognize their full potential through holistic education directed towards developing human beings with a global conscience, a vision of peace, love and emotional intelligence, which in the authors' view are significant traits to navigate the future of Industrial Revolution 5.0. The concept of holistic education thus emphasises on equipping children with facing the realities of life which includes the challenges in differential situation and environment. This article highlights that holistic education is a very much needed and necessitated concept that should be inculcated in the education curriculum. Education is the primary tool that prepares man-kind for the many facets of life which should include mental health. Literature review reflects that the education curriculum in Malaysia does not prioritise the imperativeness of mental health in the education system. For example, the covid-19 pandemic reflected of how ill equipped the society was specifically in the purview of mental health which saw both adults and children struggling to face the pandemic. Reports of suicide, child abuse, marriage break-up, depression were the consequences that the pandemic brought about apart from facing the illness itself and economic downturn that people suffered in Malaysia. Malaysia should take a bold step similar to that taken by the Finnish government to transform the current education system to meet the demands of the industry and promote mental wellness through holistic education which subsequently liberates children's mind and cognitive abilities in positive ways to live and survive the many challenges of life.

\section{References}

Malaysia. (2011). National health and morbidity survey (NMRR-10-757-6837). Kuala Lumpur: Institute for Public Health, National Institutes of Health, Ministry of Health, Malaysia.

Coker, K. L., Smith, P. H., Westphal, A., Zonana, H. V., \& McKee, S. A. (2014). Crime and psychiatric disorders among youth in the US population: an analysis of the National Comorbidity Survey-Adolescent Supplement. Journal of the American Academy of Child and Adolescent Psychiatry, 53(8), 888-898.e8982. 
https://doi.org/10.1016/j.jaac.2014.05.007

Sinniah, A., Maniam, T., Oei, T. P., \& Subramaniam, P. (2014). Suicide attempts in Malaysia from the year 1969 to 2011. The Scientific World Journal, 718367. https://doi.org/10.1155/2014/.

Abdi, S. (2009). Does suicide always indicate a mental illness? London Journal of Primary Care, 2:2, 93-94, DOI: 10.1080/17571472.2009.11493259

Coentre, R., Faravelli, C., \& Figueira, M. L. (2016). Assessment of depression and suicidal behaviour among medical students in Portugal. International journal of medical education, 7, 354-363. https://doi.org/10.5116/ijme.57f8.c468.

Nahavandi, S. (2019). Industry 5.0-A Human-Centric Solution. Sustainability, 11(16), 4371. MDPI AG. Retrieved from http://dx.doi.org/10.3390/su11164371.

Forbes, S. (2003). Holistic education: An analysis of its ideas and nature. Brandon, VT: Foundation for Educational Renewal (Solomon Press).

Narve, R.G. (2001). Holistic education: Pedagogy of universal love. Brandon, VT: Foundation for Educational Renewal.

Haradhan, M. (2019) The first industrial revolution: Creation of a new global human era. J Soc Sci Humanit. Vol. 5, No. 4, pp. 377-387.

Wahid, N., Hazlina, H., Low, S., \& Ashhari Z., M.(2011). Malaysian education system reform: Educationists perspectives. Proceedings of the International Conference on Social Science, Economics and Art.

Symeonidis, V., \& Schwarz, J. F. (2016). Phenomenon-based teaching and learning through the pedagogical lenses of phenomenology: The recent curriculum reform in finland. Forum Oświatowe, 28(2), 31-47. Retrieved fromhttp://forumoswiatowe.pl/index.php/czasopismo/article/view/458.

Carl J. (2009) Industrialization and public education: Social cohesion and social stratification. In: Cowen R., Kazamias A.M. (eds) International Handbook of Comparative Education. Springer International Handbooks of Education, vol 22. Springer, Dordrecht. https://doi.org/10.1007/978-1-4020-6403-6_32

Toffler, A. (1974). Learning for tomorrow: The role of the future in education. Vintage Books,. Weare, K. (2005). Taking a positive, holistic approach to the mental and emotional health and well-being of children and young people. In C. Newnes and N. Radcliffe (Eds.), Making and breaking children's lives (pp.115-122). Ross-on-Wye: PCCCS Books.

Freud, S. (1923). The Ego and the Id. In J. Strachey et al. (Trans.), The Standard Edition of the Complete Psychological Works of Sigmund Freud, Volume XIX. London: Hogarth Press.

Borg-Laufs, M. (2013). Basic Psychological Needs in Childhood and Adolescence. Journal of Education and Research, 3(1), 41-51. https://doi.org/10.9771/64

World Health Organisation.(2005). Promoting Mental Health. ISBN 9241562943.

Miller, R. (1997). What are schools for? Holistic education in American culture. $3^{\text {rd }}$ Edition. Brandon, Vt: Holistic Education Press.

Tremmel, R. (2006). Changing the Way We Think in English Education: A Conversation in the Universal Barbershop. English Education, 39(1), 10-45. http://www.jstor.org/stable/40173235

Winzer, R., Lindberg, L., Guldbrandsson, K., \& Sidorchuk, A. (2018). Effects of mental health interventions for students in higher education are sustainable over time: a systematic review and meta-analysis of randomized controlled trials. PeerJ, 6, e4598. https://doi.org/10.7717/peerj.4598

Krishnamurti, J. (1974). Krishnamurti on education. New Delhi: Orient Longman. 
BBC. (2015). "The runaway children Malaysia failed to save." BBC. https://www.bbc.com/news/magazine-35161791.

Jantan, R., \& Ahmad, A. (2013). Literacy and psychosocial problems among aboriginal students in primary school in Cameron Highlands (Malaysia). Int Educ Res J.Vol.1 No.9.

Wilson, L. (2006). Curriculum course packets ED 721 \& 726, unpublished.

Kincheloe, J. L. (2012). Critical pedagogy in the twenty-first century: evolution for survival. Counterpoints, 422, 147-183. http://www.jstor.org/stable/42981758

Clark, E. T. (1991). "Holistic education: a search for wholeness." In new directions in education, edited by Ron Miller, 53-62. Brandon, Vermont: Holistic Education Press.

Gidley, J. (2008). Turning tides: Creating dialogue between Rudolf Steiner and $21^{\text {st }}$ Century academic discourses. NSW; Rudolf Steiner Schools of Australia.

Montessori, M. (1964). The Montessori method. New York: Stockmen Books.

Krishnamurti, J. (1974). Krishnamurti on education. New Delhi: Orient Longman.

Forbes, S. (2003). Holistic education: An analysis of its ideas and nature. Brandon, VT: Foundation for Educational Renewal (Solomon Press).

Halinen, I. (2018). The new educational curriculum in Finland. In M. Matthes, L. Pulkkinen, C. Clouder, \& B. Heys (Eds.), Improving the quality of childhood in Europe (Vol. 7) (pp. 7589). Brussels, Belgium: Alliance for Childhood European Network Foundation. Retrieved from http://www.allianceforchildhood.eu/files/ Improving_the_quality_of_Childhood_Vol_7/QOC\%20V7\%20CH06\%20DEF\%20WEB.p df

Ministry of Education and Culture. (2012). Education and research2011-2016: A development plan.

Soby, M. (2015). Finnish education system. Nordic Journal of Digital Literacy.Vol 10.

Wahid, N., Hazlina, H., Low, S., \& Zariyawati, A. M. (2011). Malaysian education system reform: educationists' perspectives. Proceedings of the International conference on Social Science, Economics and Art.

Radha, R. (2019). Swami Vivekananda's mission on man making education. International Journal of Emerging Technologies and Innovative Research.

Narve, R. G. (2001). Holistic education: Pedagogy of universal love. Brandon, VT: Foundation for Educational Renewal. 